CLINICAL STUDY

\title{
Metformin is associated with improved left ventricular diastolic function measured by tissue Doppler imaging in patients with diabetes
}

Charlotte Andersson, Peter Søgaard, Søren Hoffmann, Peter R Hansen, Allan Vaag ${ }^{1}$, Atheline Major-Pedersen ${ }^{2}$, Thomas Fritz Hansen, Jan Bech, Lars Køber ${ }^{3}$, Christian Torp-Pedersen and Gunnar H Gislason

Department of Cardiology, Copenhagen University Hospital, Gentofte, Copenhagen, Denmark, ${ }^{1}$ Steno Diabetes Centre, Gentofte, Copenhagen, Denmark, ${ }^{2}$ Division of Endocrinology, Department of Internal Medicine, Copenhagen University Hospital, Gentofte, Copenhagen, Denmark and ${ }^{3}$ The Heart Centre, Copenhagen University Hospital, Rigshospitalet, Copenhagen, Denmark

(Correspondence should be addressed to C Andersson who is now at Department of Cardiology, Gentofte University Hospital, Niels Andersens Vej 65, DK 2900 Hellerup, Denmark; Email: ca@heart.dk)

\begin{abstract}
Objective: To examine the association between selected glucose-lowering medications and left ventricular (LV) diastolic function in patients with diabetes.

Design: Retrospective cohort study (years 2005-2008).

Methods: Echocardiograms of 242 patients with diabetes undergoing coronary angiography were analyzed. All patients had an LV ejection fraction (LVEF) $\geq 20 \%$ and were without atrial fibrillation, bundle branch block, valvular disease, or cardiac pacemaker. Patients were grouped according to the use of metformin $(n=56)$, sulfonylureas $(n=43)$, insulin $(n=61)$, and combination treatment $(n=82)$. Results: Mean age (66 \pm 10 years) and mean LVEF ( $45 \pm 11 \%)$ were similar across the groups. Mean isovolumic relaxation time (IVRT) was $66 \pm 31,79 \pm 42,69 \pm 23$, and $66 \pm 29 \mathrm{~ms}$ in metformin, sulfonylureas, insulin, and combination treatment groups respectively $(P=0.4)$. Mean early diastolic longitudinal tissue velocity $\left(e^{\prime}\right)$ was $5.3 \pm 1.6,4.6 \pm 1.6,5.3 \pm 1.8$, and $5.4 \pm 1.7 \mathrm{~cm} / \mathrm{s}$ in metformin, sulfonylureas, insulin, and combination treatment groups $(P=0.04)$. In adjusted linear regression models, the use of metformin was associated with a shorter IVRT (parameter estimate $-9.9 \mathrm{~ms}$, $P=0.049$ ) and higher $e^{\prime}$ (parameter estimate $+0.52 \mathrm{~cm} / \mathrm{s}, P=0.03$ ), compared with no use of metformin. The effects of metformin were not altered by concomitant use of sulfonylureas or insulin ( $P$ for interactions $>0.4$ ).

Conclusions: The use of metformin is associated with improved LV relaxation, as compared with no use of metformin.
\end{abstract}

European Journal of Endocrinology 163 593-599

\section{Introduction}

Diabetes is a potent risk factor for heart failure and an adverse prognosticator hereof $(1,2)$. Although common risk factors such as hypertension and coronary artery disease (CAD) contribute to such relationships, increasing evidence suggests that insulin resistance and diabetes may have a direct negative influence on cardiac function, i.e. diabetic cardiomyopathy $(3,4)$. In the presence of insulin resistance, cardiac metabolism changes toward increased fatty acid utilization and decreased glucose consumption $(5,6)$. These changes are thought to promote altered myocardial relaxation and diastolic dysfunction $(4,7)$, which subsequently can lead to clinical heart failure (8). Metformin has been hypothesized to improve cardiac metabolism and function in diabetes patients, and experimental studies have recently demonstrated that metformin can attenuate the development of heart failure $(9,10)$. However, it is still unknown whether metformin has detectable beneficial effects on cardiac function.

Echocardiographic tissue Doppler imaging (TDI) techniques have proved useful in detecting small and potentially subclinical impairments of cardiac function. We recently demonstrated that diabetes was associated with remarkably reduced early diastolic $\left(e^{\prime}\right)$ and a slightly reduced peak systolic $\left(S^{\prime}\right)$ longitudinal tissue velocity among patients without CAD, with no detectable influence on conventional echocardiography parameters (11). Other studies have found similar results (12-15).

Given a potential association between diabetic cardiomyopathy, diastolic function, and effects of metformin, we investigated the relationship between the use of different glucose-lowering agents and left ventricular (LV) relaxation as determined by isovolumic relaxation time (IVRT) and $e^{\prime}$ in a cohort of diabetes patients. 


\section{Methods}

All echocardiograms performed at Gentofte University Hospital, a tertiary invasive center, have been digitally stored since mid 2005. Examinations were performed according to a standardized protocol and included tissue Doppler investigations. All coronary angiography data were also registered in a local database since 1999. Patients were registered with information on coronary pathology, major comorbidities, history of heart diseases, and cardiovascular risk factors, including diabetes and diabetes treatment (i.e. diet, oral glucoselowering medications, or insulin). The diagnosis of diabetes was based on patient history and blood glucose levels. The diagnoses of hypertension and dyslipidemia were based on patient history and also required the use of pharmacological treatment. The diagnosis of clinical heart failure relied on the clinical evaluation at the time of coronary angiography.

We identified all patients with diabetes requiring glucose-lowering medications, who were subjected to coronary angiography for suspected or known ischemic heart disease between mid 2005 and end 2008. Patients who had an echocardiography performed in temporal proximity to their respective coronary angiography were included in this study. All echocardiograms were evaluated individually, and those where complete tissue Doppler investigations were available and where patients did not have atrial fibrillation, bundle branch block, significant valve disease, cardiac pacemaker, congenital heart disease, and/or LV ejection fraction (LVEF) $<20 \%$ were included in the study.

\section{Echocardiography analyses}

All echocardiograms were obtained using GE Vivid 7 ultrasound system. All records were analyzed by the same investigator (C A), who was blinded to knowledge of diabetes medication, using Echopac '08 software (GE Medical Systems, Horton, Norway). Inter- and intraobserver variations have been reported previously (11).

$\mathrm{LV}$ end diastolic dimensions (interventricular septum wall thickness, end diastolic inner diameter, and posterior wall thickness) were obtained from the parasternal long-axis view. Biplane LVEF was obtained using Simpson's method. Left atrial end systolic dimensions were estimated from the apical four- and two-chamber views. Diastolic function was assessed using transmitral flow velocity profiles (obtained by pulsed-wave Doppler) and TDI velocities from the lateral and medial mitral annulus, in agreement with the criteria accepted by the Canadian Consensus on Diastolic Dysfunction (16). IVRT was obtained by measurements from pulsed-wave TDI velocities in the medial and lateral walls of the apical four-chamber view (an average between the two values).
LV longitudinal peak velocities were obtained from two-dimensional color-coded tissue Doppler image loops (offline measurements). The peak systolic $\left(S^{\prime}\right)$, early diastolic $\left(e^{\prime}\right)$, and atrial $\left(a^{\prime}\right)$ tissue velocities were measured in the basal segments just proximal to the mitral annulus. A sample width and height of $7 \times 15 \mathrm{~mm}$ was used. Values presented were mean values from both sides of three apical views (i.e. fourchamber, two-chamber, and apical long-axis views).

\section{Identification of pharmacotherapy}

Echocardiographic data were linked at an individual level to the Danish Register of Medicinal Product Statistics, a nationwide register that held information on all dispensed prescriptions from Danish pharmacies since 1995. All drugs were registered according to the Anatomical Therapeutic Chemical (ATC) classification system. The register has previously been shown to be complete and accurate (17). The use of a specific glucose-lowering agent was defined as at least one claimed prescription for the specific agent in the 6 months prior to echocardiography, and another claimed prescription for the same agent between 7 and 12 months prior to echocardiography. The following agents (ATC codes) were identified: metformin (A10BA02), sulfonylureas (A10BB), insulin (A10A), and glitazones (A10BG). However, patients using glitazones were not included in the analysis as only a few patients used these agents $(n=32$, of whom only 6 used them as monotherapy). Patients included were grouped according to the use of metformin, insulin, or sulfonylureas in the respective monotherapy group, or in a 'combination group' if using more than one agent. For other medications, patients were considered to be in treatment with a specific agent if they had claimed at least one prescription in the 6 months preceding echocardiography. To determine concomitant pharmacotherapy, the following agents (ATC codes) were identified: $\beta$-blockers (C07), statins (C10A), angiotensin-converting enzyme inhibitors and angiotensin-2 antagonists (C09), loop diuretics (C03C), thiazides (CO3A), spironolactone (CO3D), and calcium channel blockers (C08), as done previously (18).

\section{Statistical analysis}

Continuous variables were compared with KruskalWallis test and discrete variables with $\chi^{2}$-test. Linear regression models were used to examine the effect of multiple parameters on $e^{\prime}$ and IVRT respectively. Included variables were chosen a priori, based on theoretical conceptions. However, to ensure that the presented estimates were not influenced by close correlation between variables, different models were performed as sensitivity analyses. All analyses were performed using SAS version 9.1 (SAS Institute, Cary, NC, USA). 


\section{Ethics}

Retrospective register-based studies do not need ethical approval in Denmark. The study was approved by the Danish Data Protection Agency (No. 2007-41-1667).

\section{Results}

\section{Study population}

Between mid 2005 and December 2008, 10964 patients underwent coronary angiography. A total of 1362 patients had diabetes requiring glucose-lowering medications, and 585 of these patients had been subjected to echocardiography. The echocardiograms from 242 patients were included as they were performed in temporal proximity to the coronary angiography and fulfilled the inclusion criteria. Baseline characteristics of the different treatment groups are shown in Table 1. Mean age was $66( \pm$ s.D. 10) years, and mean LVEF was $45 \pm 11 \%$, which were similar across the groups $(P=0.09$ and 1.0 respectively). In total, $13 \%$ of the study population had a pseudonormalized or restrictive diastolic function $(P$ for difference between groups $=0.8$ ). Myocardial infarction was diagnosed in $30 \%$ of the patients $(P$ for difference between groups $=0.3)$, and $26 \%$ of the study population had clinical heart failure $(P$ for difference between groups $=0.4)$. Patients using metformin had a significantly lower prevalence of prior myocardial infarction compared with patients using other glucose-lowering medications ( 18 vs $32 \%, P=0.01$ ).

\section{Effect of metformin on IVRT}

In the unadjusted analysis, IVRT tended to be lower in patients using metformin, compared with patients not using metformin (IVRT $66 \pm 30$ vs $72 \pm 32 \mathrm{~ms}, P=0.1$ ). After adjustment for all variables shown in Table 2, the use of metformin was significantly associated with an improvement in IVRT (parameter estimate - $9.9(95 \%$ confidence interval (CI) $-19.8,-0.04) \mathrm{ms}, P=0.049$; Table 2). The effect of metformin on IVRT was not dependent on concomitant use of sulfonylureas or insulin ( $P$ for interactions $=0.6$ and 0.4 respectively), and was not modified by LV end diastolic posterior wall thickness, LVEF, or diabetes duration ( $P$ for interactions $=0.2,0.4$, and 0.6 respectively). In analysis without patients classified as having pseudonormalized or restrictive filling pattern, metformin remained associated with improved IVRT (parameter estimate $-10.7(95 \% \mathrm{CI}-21.1,-0.3) \mathrm{ms}, P=0.04)$.

\section{Effect of metformin on $\mathrm{e}^{\prime}$}

Patients using metformin also tended to have slightly higher $e^{\prime}$ compared with patients not using metformin (mean $e^{\prime} 5.4 \pm 1.7$ vs $5.0 \pm 1.7 \mathrm{~cm} / \mathrm{s}, P=0.07$ ). After adjustment for other variables, the use of metformin was associated with an increase in $e^{\prime}$ (parameter estimate $+0.52(95 \% \mathrm{CI} 0.06,0.97) \mathrm{cm} / \mathrm{s}, P=0.03)$. The effect of metformin on $e^{\prime}$ was not altered by concomitant use of insulin or sulfonylureas $(P$ for interactions $=0.6$ and $P=0.7$ respectively), and was not dependent on diabetes duration ( $P$ for interaction between diabetes duration and metformin $=0.3$ ), LVEF $(P$ for interaction $=0.5)$, or $\mathrm{LV}$ end diastolic posterior wall thickness $(P$ for interaction $=0.7)$ respectively. Exclusion of patients with pseudonormalized or restrictive filling pattern from the analysis provided similar results for metformin treatment (parameter estimate $+0.53(95 \%$ CI $0.03,1.04) \mathrm{cm} / \mathrm{s}, P=0.04)$.

\section{Discussion}

In this study, we investigated the relationship between the use of different glucose-lowering medications and the LV diastolic function in a cohort of diabetes patients. We found that the use of metformin was associated with significantly shorter IVRT and higher $e^{\prime}$, whereas the use of insulin or sulfonylureas was not.

Both of the studied LV diastolic parameters, IVRT and $e^{\prime}$, represent the early part of diastole, where active myocardial relaxation occurs. By including steps such as the release of calcium from troponin C, detachment of actin-myosin cross-bridges, and extension of sarcomeres to their resting length, this process is indeed highly energy consuming (19). Specifically, IVRT reflects the LV relaxation rate, which therefore presumably relates to the global myocardial function and myocardial energy provision. Supporting such supposition, IVRT has been shown to improve with short-term training among sedentary subjects (20). Similarly, $e^{\prime}$ is primarily dependent on LV relaxation and reflects a combination of active, energy-consuming steps plus elastic recoil representing the cyclic restoration forces of the myocardium (21). $E^{\prime}$ has shown to be rather independent of LV preload $(22,23)$, to decrease with diminished coronary blood flow, and to improve with exercise $(20,24)$.

There are various mechanisms by which metformin could contribute to shortened IVRT and improved $e^{\prime}$, and some of these mechanisms may be independent of the blood glucose-lowering effect of the agent.

\section{Myocardial energy supply}

Although we did not examine this issue specifically in our study cohort, it may be hypothesized that the majority of patients were insulin resistant. Insulin resistance and diabetes are known to change myocardial metabolism toward increased fatty acid utilization and decreased glucose consumption, which may be sufficient for basal cardiac metabolic requirements (5). In the presence of noxious stimuli such as myocardial 
Table 1 Baseline characteristics of the different treatment groups.

\begin{tabular}{|c|c|c|c|c|c|}
\hline & $\begin{array}{l}\text { Metformin } \\
(n=56)\end{array}$ & $\begin{array}{l}\text { Insulin } \\
(n=61)\end{array}$ & $\begin{array}{l}\text { Sulfonylureas } \\
(n=43)\end{array}$ & $\begin{array}{l}\text { Combination } \\
(n=82)\end{array}$ & $\begin{array}{l}P \text { for } \\
\text { difference }\end{array}$ \\
\hline Proportion of study population (\%) & $23 \%$ & $25 \%$ & $18 \%$ & $34 \%$ & \\
\hline Gender, male (\%) & $80 \%$ & $59 \%$ & $74 \%$ & $78 \%$ & 0.03 \\
\hline Age (years) & $67( \pm 8)$ & $63( \pm 12)$ & $69( \pm 9)$ & $65( \pm 10)$ & 0.09 \\
\hline Body mass index $\left(\mathrm{kg} / \mathrm{m}^{2}\right)$ & $30( \pm 5)$ & $28( \pm 5)$ & $28( \pm 5)$ & $29( \pm 5)$ & 0.05 \\
\hline History of myocardial infarction (\%) & $11 \%$ & $30 \%$ & $33 \%$ & $24 \%$ & 0.04 \\
\hline History of arterial hypertension (\%) & $73 \%$ & $72 \%$ & $79 \%$ & $71 \%$ & 0.8 \\
\hline History of dyslipidemia (\%) & $79 \%$ & $74 \%$ & $81 \%$ & $74 \%$ & 0.5 \\
\hline Clinical heart failure (\%) & $25 \%$ & $31 \%$ & $33 \%$ & $21 \%$ & 0.4 \\
\hline Acute myocardial infarction (\%) & $23 \%$ & $33 \%$ & $23 \%$ & $35 \%$ & 0.3 \\
\hline Chronic pulmonary obstructive disease (\%) & $9 \%$ & $8 \%$ & $14 \%$ & $6 \%$ & 0.5 \\
\hline Smoking (\%) & $34 \%$ & $21 \%$ & $21 \%$ & $24 \%$ & 0.4 \\
\hline Diabetes duration (years) ${ }^{\mathrm{b}}$ & $3.2(2.1,5.8)$ & $11.6(9.8,12.3)$ & $3.9(2.3,7.8)$ & $7.8(5.0,11.4)$ & $<0.0001$ \\
\hline Duration of metformin treatment (years) ${ }^{\mathrm{c}}$ & $2.7(1.9,4.6)$ & - & - & $4.7(2.8,7.0)$ & - \\
\hline Duration of sulfonylureas treatment (years) ${ }^{c}$ & - & - & $3.8(2.3,7.8)$ & $7.8(4.7,11.2)$ & - \\
\hline Duration of insulin treatment (years) ${ }^{\mathrm{C}}$ & - & $11.0(6.4,12.0)$ & - & $3.0(1.4,6.8)$ & - \\
\hline \multicolumn{6}{|l|}{ Concomitant medical therapy } \\
\hline Loop diuretics & $23 \%$ & $34 \%$ & $26 \%$ & $34 \%$ & 0.4 \\
\hline Thiazides & $18 \%$ & $23 \%$ & $21 \%$ & $16 \%$ & 0.7 \\
\hline RAS inhibitors & $68 \%$ & $71 \%$ & $79 \%$ & $77 \%$ & 0.5 \\
\hline Spironolactone & $11 \%$ & $11 \%$ & $7 \%$ & $7 \%$ & 0.8 \\
\hline Statins & $70 \%$ & $66 \%$ & $77 \%$ & $79 \%$ & 0.3 \\
\hline Calcium channel blockers & $38 \%$ & $38 \%$ & $30 \%$ & $43 \%$ & 0.6 \\
\hline$\beta$-Blockers & $55 \%$ & $46 \%$ & $53 \%$ & $46 \%$ & 0.6 \\
\hline \multicolumn{6}{|l|}{ Coronary angiography } \\
\hline Single vessel disease & $14 \%$ & $14 \%$ & $13 \%$ & $21 \%$ & 0.5 \\
\hline Two vessel disease & $25 \%$ & $18 \%$ & $15 \%$ & $18 \%$ & 0.6 \\
\hline Three vessel disease & $39 \%$ & $48 \%$ & $64 \%$ & $45 \%$ & 0.2 \\
\hline $\begin{array}{l}\text { Diffuse coronary artery disease, } \\
\text { no significant stenoses }\end{array}$ & $6 \%$ & $13 \%$ & $3 \%$ & $6 \%$ & 0.3 \\
\hline No coronary artery disease & $16 \%$ & $7 \%$ & $5 \%$ & $10 \%$ & 0.3 \\
\hline \multicolumn{6}{|l|}{ Echocardiography investigation } \\
\hline $\begin{array}{l}\text { Interventricular septum thickness, } \\
\text { end diastolic (mm) }\end{array}$ & $1.1( \pm 0.3)$ & $1.2( \pm 0.3)$ & $1.2( \pm 0.2)$ & $1.2( \pm 0.2)$ & 0.3 \\
\hline LV diamenter, end diastolic (mm) & $5.0( \pm 0.7)$ & $4.8( \pm 0.6)$ & $4.9( \pm 0.8)$ & $5.0( \pm 0.8)$ & 0.8 \\
\hline LV posterior wall thickness, end diastolic $(\mathrm{mm})$ & $1.1( \pm 0.2)$ & $1.1( \pm 0.2)$ & $1.2( \pm 0.2)$ & $1.1( \pm 0.2)$ & 0.1 \\
\hline Deceleration time $(\mathrm{ms})$ & $204( \pm 51)$ & $226( \pm 66)$ & $197( \pm 61)$ & $215( \pm 60)$ & 0.2 \\
\hline Biplane left ventricular ejection fraction (\%) & $45( \pm 11)$ & $46( \pm 12)$ & $45( \pm 12)$ & $46( \pm 11)$ & 1.0 \\
\hline Left atrial end systolic dimension (ml) & $49( \pm 21)$ & $46( \pm 22)$ & $46( \pm 22)$ & $46( \pm 22)$ & 0.7 \\
\hline \multicolumn{6}{|l|}{ Diastolic function classification ${ }^{\mathrm{d}}$} \\
\hline Normal & $42 \%$ & $50 \%$ & $43 \%$ & $52 \%$ & \\
\hline Impaired relaxation & $42 \%$ & $40 \%$ & $40 \%$ & $35 \%$ & \\
\hline Pseudonormalization & $13 \%$ & $9 \%$ & $10 \%$ & $10 \%$ & \\
\hline Restrictive filling & $2 \%$ & $2 \%$ & $8 \%$ & $3 \%$ & \\
\hline \multicolumn{6}{|l|}{ Tissue Doppler-derived parameters } \\
\hline Average $S^{\prime}(\mathrm{cm} / \mathrm{s})$ & $5.0( \pm 1.1)$ & $4.9( \pm 1.2)$ & $4.6( \pm 1.3)$ & $5.1( \pm 1.3)$ & 0.2 \\
\hline Average $e^{\prime}(\mathrm{cm} / \mathrm{s})$ & $5.3( \pm 1.6)$ & $5.3( \pm 1.8)$ & $4.6( \pm 1.6)$ & $5.4( \pm 1.7)$ & 0.04 \\
\hline Average $a^{\prime}(\mathrm{cm} / \mathrm{s})$ & $6.4( \pm 1.9)$ & $6.2( \pm 1.9)$ & $6.3( \pm 2.5)$ & $6.2( \pm 2.0)$ & 1.0 \\
\hline$E: e^{\prime}$ ratio & $11.3( \pm 4.7)$ & $11.2( \pm 4.7)$ & $11.7( \pm 4.4)$ & $10.4( \pm 3.5)$ & 0.5 \\
\hline IVRT (ms) & $66( \pm \overline{31})$ & $69( \pm 23)$ & $79( \pm 42)$ & $66( \pm 29)$ & 0.4 \\
\hline
\end{tabular}

RAS inhibitors, angiotensin-converting enzyme inhibitors and angiotensin-2 receptor blockers; IVRT, isovolumic relaxation time.

${ }^{\mathrm{a}} 91 \%$ metformin, $44 \%$ insulin, and $67 \%$ sulfonylureas.

${ }^{\mathrm{b}}$ Refers to first claimed prescription of any glucose-lowering medication since 1995.

${ }^{\mathrm{c}}$ Refers to first claimed prescription of the specific agent since 1995. Numbers are presented as median (interquartile range).

${ }^{d}$ In agreement with the Canadian consensus recommendations for measurement and reporting of diastolic dysfunction by echocardiography (16).

ischemia, however, the heart normally responds by altering its substrate metabolism toward increased glucose consumption (which generates more ATP per unit oxygen consumed than does fatty acid oxidation), but insulin resistance prevents this adaptive response and can therefore lead to energy depletion and myocardial injury (5). Considering that the majority of the study population had CAD at the time of investigation, metformin use may have attenuated such injury. On the molecular level, metformin is known to act by stimulating AMP kinase (AMPK), an enzyme with a central role in regulation of cardiac energy metabolism under stressed conditions (25). Physiologically, AMPK is stimulated by increased ADP:ATP ratio and once activated, AMPK switches on catabolic pathways for generation of ATP (26). 
Through its actions on AMPK, administration of metformin has been shown earlier to attenuate pacing-induced heart failure progression in dogs (10), and to attenuate the subsequent impairments of cardiocyte mitochondrial respiration and ATP synthesis in mice subjected to occlusion of the left coronary artery (9). In potential line with these considerations, we found that a history of (medically treated) dyslipidemia had a significantly negative influence on IVRT and $e^{\prime}$, which would agree with the findings of a previous study (7). As assessments of myocardial fat content and insulin resistance were not performed in our study, however, closer examination of the relationship between myocardial function and metabolism in patients with dyslipidemia and statin treatment requires further investigations.

\section{Blood flow alterations}

As alterations of myocardial diastolic function are among the earliest functional consequences of myocardial ischemia (27), the observed effects of metformin may in part be explained by improved myocardial microcirculation. At least, two studies in populations without any apparent heart disease, one including women with polycystic ovary syndrome and the other including patients with well-regulated type 2 diabetes, reported significant increases in cardiac blood flow with metformin treatment $(28,29)$. Furthermore, metformin treatment in women with polycystic ovary syndrome was recently reported to cause improvements in endothelial function and arterial stiffness, possibly due to decreased insulin resistance (30). In addition, metformin treatment has been associated with increased phosphorylation of endothelial nitric oxide synthase and plasma nitric oxide levels in dogs with heart failure, and such mechanisms may have contributed to our current observations (10).

\section{Cardiac fibrosis}

It is also possible that the association between metformin and the improvements of LV diastolic parameters to some extent was due to diminished cardiac fibrosis and reduced cross-linkage of advanced glycemic end products, which are known to increase ventricular stiffness thereby leading to prolonged IVRT and impaired $e^{\prime}$. For example, one experimental study of diabetic mice demonstrated that chronic use of metformin prevented the formation of collagen-linked

Table 2 Influence of different factors on $e^{\prime}$ and IVRT respectively. Results from multivariable regression analyses.

\begin{tabular}{|c|c|c|c|c|}
\hline & $\begin{array}{l}\text { Estimated influence } \\
\text { on } \boldsymbol{e}^{\prime}(\mathrm{cm} / \mathrm{s})\end{array}$ & $P$ value & $\begin{array}{l}\text { Estimated influence } \\
\text { on IVRT (ms) }\end{array}$ & $P$ value \\
\hline Age, for 10 years increase & $-0.57(-0.79,-0.35)$ & $<0.0001$ & $3.9(-9.9,8.7)$ & 0.1 \\
\hline $\begin{array}{l}\text { Left ventricular ejection fraction, } \\
\text { for } 10 \% \text { units increase }\end{array}$ & $0.35(0.17,0.54)$ & $<0.001$ & $-4.7(-8.8,-0.7)$ & 0.02 \\
\hline History of dyslipidemia & $-0.84(-1.38,-0.31)$ & $<0.01$ & $12.2(0.20,24.2)$ & 0.046 \\
\hline Calcium channel blockers & $-0.47(-0.87,-0.06)$ & 0.02 & $-12.5(-21.3,-3.7)$ & $<0.01$ \\
\hline Metformin & $0.52(0.06,0.97)$ & 0.03 & $-9.9(-19.8,-0.04)$ & 0.049 \\
\hline $\begin{array}{l}\text { Left ventricle posterior wall thickness, } \\
\text { for } 1 \mathrm{~mm} \text { increase }\end{array}$ & $-0.10(-0.19,-0.006)$ & 0.04 & $15.7(-4.3,35.6)$ & 0.1 \\
\hline Statins & $0.45(-0.03,0.93)^{a}$ & 0.06 & $2.3(-8.1,12.8)$ & 0.7 \\
\hline Loop diuretics & $-0.39(-0.84,0.07)$ & 0.1 & $-0.9(-10.7,8.9)$ & 0.9 \\
\hline Thiazides & $0.39(-0.11,0.88)$ & 0.1 & $5.8(-5.2,16.7)$ & 0.3 \\
\hline Gender, male & $0.39(-0.09,0.87)$ & 0.1 & $-0.2(-10.5,10.2)$ & 1.0 \\
\hline$\beta$-Blockers & $-0.29(-0.68,0.11)$ & 0.2 & $-5.4(-14.2,3.4)$ & 0.2 \\
\hline Body mass index, for $1 \mathrm{~kg} / \mathrm{m}^{2}$ & $-0.02(-0.06,0.02)$ & 0.3 & $0.3(-0.55,1.21)$ & 0.5 \\
\hline Diabetes duration, for 1 year & $0.02(-0.04,0.08)$ & 0.4 & $-0.01(-1.3,1.3)$ & 1.0 \\
\hline History of myocardial infarction & $0.18(-0.28,0.65)$ & 0.4 & $4.3(-5.9,14.5)$ & 0.4 \\
\hline Acute myocardial infarction & $-0.16(-0.60,0.28)$ & 0.5 & $3.4(-6.1,12.9)$ & 0.5 \\
\hline History of hypertension & $0.18(-0.33,0.68)$ & 0.5 & $0.5(-10.5,11.5)$ & 0.9 \\
\hline Insulin & $0.16(-0.45,0.78)$ & 0.6 & $-6.5(-19.9,6.9)$ & 0.3 \\
\hline Clinical heart failure & $-0.13(-0.60,0.34)$ & 0.6 & $-5.3(-15.6,5.1)$ & 0.3 \\
\hline No coronary artery disease & $0.24(-0.56,1.03)$ & 0.6 & $-1.6(-19.3,16.1)$ & 0.9 \\
\hline Chronic obstructive pulmonary disease & $0.14(-0.54,0.81)$ & 0.7 & $-15.8(-31.2,-0.4)$ & 0.045 \\
\hline ACE inhibitors & $-0.07(-0.55,0.41)$ & 0.8 & $-4.6(-15.4,6.2)$ & 0.4 \\
\hline Smoking & $-0.06(-0.51,0.39)$ & 0.8 & $-10.7(-20.6,-0.7)$ & 0.04 \\
\hline Single vessel disease & $-0.05(-0.77,0.68)$ & 0.9 & $7.8(-7.8,23.3)$ & 0.3 \\
\hline Three vessel disease & $-0.008(-0.21,0.19)$ & 0.9 & $-2.3(-6.6,2.0)$ & 0.3 \\
\hline Two vessel disease & $0.03(-0.64,0.70)$ & 0.9 & $3.3(-11.3,17.9)$ & 0.7 \\
\hline Sulfonylureas & $-0.04(-0.52,0.44)$ & 0.9 & $-1.5(-12.0,9.0)$ & 0.8 \\
\hline Spironolactone & $-0.06(-0.76,0.65)$ & 0.9 & $9.6(-6.2,25.4)$ & 0.2 \\
\hline
\end{tabular}

Results from multivariable linear regression analyses of $e^{\prime}$ and IVRT respectively. Variables are presented after significance level in $e^{\prime}$ regression analysis, with most significant values on top.

a Parameter estimate should be interpreted with caution; analysis without dyslipidemia resulted in parameter estimate $0.21(-0.24,0.66), P=0.4$. 
advanced glycosylation end products, and another study found that administration of metformin inhibited cardiac fibrosis induced by pressure overload in nondiabetic mice $(31,32)$.

\section{Clinical implications}

As discussed above, experimental evidence indicates that metformin may exert beneficial effects on cardiac function, and data from this study suggest that such effects can be clinically important. From a clinical point of view, the sum of evidence therefore suggests that metformin treatment should not be omitted or discontinued in diabetes patients with ischemic heart disease or heart failure, which, however, is often the case in clinical practice today. The major reason clinicians do not prescribe metformin to these patients is the concern for lactic acidosis. However, the incidence of lactic acidosis due to metformin treatment even in high-risk patients, i.e. patients with heart failure, having procedures requiring iodinated contrast, and/or patients with renal impairment, seems to be very small (33), and data actually suggest that metformin is associated with improved survival in heart failure patients (34).

\section{Strengths and limitations of the study}

The major strengths of the study includes the availability of sensitive echocardiography parameters, coronary angiography results, and supplementary clinical data. However, we acknowledge the inability of distinguishing type 1 from type 2 diabetes in the study. Furthermore, we acknowledge the lack of data on blood biochemistry parameters such as HbAlc, measurements of insulin resistance, and creatinine clearance, which may have confounded our results. Indeed, metformin is presently used as first-line therapy in patients with the mildest diabetes phenotypes and without contraindications (heart failure or renal insufficiency). Therefore, we cannot exclude that some degree of residual hidden confounder contributed to the improved diastolic function associated with metformin treatment. Accordingly, this observational study does not allow for any conclusion on causality, i.e. whether metformin has a direct beneficial effect on myocardial function, but by generating such hypothesis, the results may provide the impetus for hypothesis testing in randomized trials. Furthermore, we did not have measurements of left atrial pressures, which could have helped in interpretation of IVRT and $e^{\prime}$. However, as rather few patients were classified as having pseudonormalized or restrictive diastolic filling pattern (in whom left atrial pressures that are thinkable could be of importance for IVRT and $e^{\prime}$ ) and as analyses without these patients provided similar results, it is unlikely that the associations between metformin and improved IVRT and $e^{\prime}$ would disappear after adjustment for left atrial pressures. Finally, although we adjusted our analyses for diabetes treatment duration since 1995, we acknowledge the possibility that some degree of residual influence on amount of cross-linkage of advanced glycemic end products may be present.

\section{Conclusions}

The results of this study indicate that metformin may have positive effects on LV relaxation in patients with diabetes. Prospective randomized studies are warranted to examine this hypothesis.

\section{Declaration of interest}

The funding source had no influence on study design, interpretation of data, or writing of manuscript. Dr A Vaag is employed by Steno Diabetes Center, which is owned by Novo Nordisk. Other authors report no relevant disclosures.

\section{Funding}

The study was supported by research grant from the Danish Agency for Science, Technology, and Innovation (Grant no. 271-08-0944).

\section{Acknowledgements}

The authors would like to thank Susan Sigvardsen, RN, for assistance with echocardiography analyses.

\section{References}

1 Kannel WB, Hjortland M \& Castelli WP. Role of diabetes in congestive heart failure: the Framingham study. American Journal of Cardiology 197434 29-34. (doi:10.1016/00029149(74)90089-7)

2 Andersson C, Weeke P, Pecini R, Kjaergaard J, Hassager C, Kober L \& Torp-Pedersen C. Long-term impact of diabetes in patients hospitalized with ischemic and non-ischemic heart failure. Scandinavian Cardiovascular Journal 200944 37-44. (doi:10. 3109/14017430903312438)

3 He J, Ogden LG, Bazzano LA, Vupputuri S, Loria C \& Whelton PK. Risk factors for congestive heart failure in US men and women: NHANES I epidemiologic follow-up study. Archives of Internal Medicine 2001 161 996-1002. (doi:10.1001/archinte.161.7.996)

4 Aneja A, Tang WH, Bansilal S, Garcia MJ \& Farkouh ME. Diabetic cardiomyopathy: insights into pathogenesis, diagnostic challenges, and therapeutic options. American Journal of Medicine $2008 \mathbf{1 2 1}$ 748-757. (doi:10.1016/j.amjmed.2008.03.046)

5 Witteles RM \& Fowler MB. Insulin-resistant cardiomyopathy clinical evidence, mechanisms, and treatment options. Journal of the American College of Cardiology 200851 93-102. (doi:10.1016/ j.jacc.2007.10.021)

6 Young ME, McNulty $\mathrm{P} \&$ Taegtmeyer $H$. Adaptation and maladaptation of the heart in diabetes: part II: potential mechanisms. Circulation 2002105 1861-1870. (doi:10.1161/ 01.CIR.0000012467.61045.87)

7 Rijzewijk LJ, van der Meer RW, Smit JWA, Diamant M, Bax JJ, Hammer S, Romijn JA, de Roos A \& Lamb HJ. Myocardial steatosis is an independent predictor of diastolic dysfunction in type 2 diabetes mellitus. Journal of the American College of Cardiology 2008 52 1793-1799. (doi:10.1016/j.jacc.2008.07.062) 
8 From AM, Scott CG \& Chen HH. The development of heart failure in patients with diabetes mellitus and pre-clinical diastolic dysfunction: a population-based study. Journal of the American College of Cardiology 201055 300-305. (doi:10.1016/j.jacc. 2009.12.003)

9 Gundewar S, Calvert JW, Jha S, Toedt-Pingel I, Ji SY, Nunez D, Ramachandran A, Anaya-Cisneros M, Tian R \& Lefer DJ. Activation of AMP-activated protein kinase by metformin improves left ventricular function and survival in heart failure. Circulation Research $2009 \mathbf{1 0 4} 403-411$. (doi:10.1161/CIRCRESAHA.108.190918)

10 Sasaki H, Asanuma H, Fujita M, Takahama H, Wakeno M, Ito S, Ogai A, Asakura M, Kim J, Minamino T, Takashima S, Sanada S, Sugimachi M, Komamura K, Mochizuki N \& Kitakaze M. Metformin prevents progression of heart failure in dogs: role of AMP-activated protein kinase. Circulation $20091192568-2577$. (doi:10.1161/CIRCULATIONAHA.108.798561)

11 Andersson C, Gislason G, Weeke P, Hoffmann S, Hansen P, TorpPedersen C \& Sogaard P. Diabetes is associated with impaired myocardial performance in patients without significant coronary artery disease. Cardiovascular Diabetology 20109 3. (doi:10.1186/ 1475-2840-9-3)

12 Di Bonito P, Moio N, Cavuto L, Covino G, Murena E, Scilla C, Turco S, Capaldo B \& Sibilio G. Early detection of diabetic cardiomyopathy: usefulness of tissue Doppler imaging. Diabetic Medicine 200522 1720-1725. (doi:10.1111/j.1464-5491. 2005.01685.x)

13 Fang ZY, Schull-Meade R, Downey M, Prins J \& Marwick TH. Determinants of subclinical diabetic heart disease. Diabetologia 200548 394-402. (doi:10.1007/s00125-004-1632-z)

14 Fang ZY, Yuda S, Anderson V, Short L, Case C \& Marwick TH. Echocardiographic detection of early diabetic myocardial disease. Journal of the American College of Cardiology $2003 \mathbf{4 1} 611-617$. (doi:10.1016/S0735-1097(02)02869-3)

15 Von Bibra H, Thrainsdottir IS, Hansen A, Dounis V, Malmberg K \& Ryden L. Tissue Doppler imaging for the detection and quantitation of myocardial dysfunction in patients with type 2 diabetes mellitus. Diabetes \& Vascular Disease Research 20052 24-30. (doi:10.3132/dvdr.2005.002)

16 Rakowski H, Appleton C, Chan KL, Dumesnil JG, Honos G, Jue J, Koilpillai C, Lepage S, Martin RP, Mercier LA, O'Kelly B, Prieur T, Sanfilippo A, Sasson Z, Alvarez N, Pruitt R, Thompson C \& Tomlinson C. Canadian consensus recommendations for the measurement and reporting of diastolic dysfunction by echocardiography: from the Investigators of Consensus on Diastolic Dysfunction by Echocardiography. Journal of the American Society of Echocardiography $1996 \mathbf{9} 736-760$. (doi:10.1016/S08947317(96)90076-0)

17 Gaist D, Sorensen HT \& Hallas J. The Danish prescription registries. Danish Medical Bulletin 199744 445-448.

18 Gislason GH, Rasmussen JN, Abildstrom SZ, Schramm TK, Hansen ML, Buch P, Sorensen R, Folke F, Gadsboll N, Rasmussen S, Kober L, Madsen M \& Torp-Pedersen C. Persistent use of evidence-based pharmacotherapy in heart failure is associated with improved outcomes. Circulation 2007116737 744. (doi:10.1161/CIRCULATIONAHA.106.669101)

19 Morgan JP. Abnormal intracellular modulation of calcium as a major cause of cardiac contractile dysfunction. New England Journal of Medicine 1991325 625-632. (doi:10.1056/NEJM 199108293250906)

20 Andersen LJ, Hansen PR, Sogaard P, Madsen JK, Bech J \& Krustrup P. Improvement of systolic and diastolic heart function after physical training in sedentary women. Scandinavian Journal of Medicine E Science in Sports 201020 50-57. (doi:10.1111/j. 1600-0838.2009.01088.x)

21 Opdahl A, Remme EW, Helle-Valle T, Lyseggen E, Vartdal T, Pettersen E, Edvardsen T \& Smiseth OA. Determinants of left ventricular early-diastolic lengthening velocity: independent contributions from left ventricular relaxation, restoring forces, and lengthening load. Circulation 2009119 2578-2586. (doi:10. 1161/CIRCULATIONAHA.108.791681)

22 Sohn DW, Chai IH, Lee DJ, Kim HC, Kim HS, Oh BH, Lee MM, Park YB, Choi YS, Seo JD \& Lee YW. Assessment of mitral annulus velocity by Doppler tissue imaging in the evaluation of left ventricular diastolic function. Journal of the American College of Cardiology $1997 \quad 30 \quad 474-480 . \quad$ (doi:10.1016/S07351097(97)88335-0)

23 Yalcin F, Kaftan A, Muderrisoglu H, Korkmaz ME, Flachskampf F, Garcia M \& Thomas JD. Is Doppler tissue velocity during early left ventricular filling preload independent? Heart 200287 336-339. (doi:10.1136/heart.87.4.336)

24 Hoffmann S, Mogelvang R, Olsen NT, Sogaard P, Fritz-Hansen T, Bech J, Galatius S, Madsen JK \& Jensen JS. Tissue Doppler echocardiography reveals distinct patterns of impaired myocardial velocities in different degrees of coronary artery disease. European Journal of Echocardiography 201011 544-549. (doi:10.1093/ ejechocard/jeq015)

25 Hardie DG. AMP-activated protein kinase: the guardian of cardiac energy status. Journal of Clinical Investigation 2004114 465-468. (doi:10.1172/JCI22683)

26 Towler MC \& Hardie DG. AMP-activated protein kinase in metabolic control and insulin signaling. Circulation Research $2007 \mathbf{1 0 0}$ 328-341. (doi:10.1161/01.RES.0000256090.42690.05)

27 Nagueh SF, Rao L, Soto J, Middleton KJ \& Khoury DS. Haemodynamic insights into the effects of ischaemia and cycle length on tissue Doppler-derived mitral annulus diastolic velocities. Clinical Science 2004106 147-154. (doi:10.1042/ CS20030204)

28 Topcu S, Tok D, Caliskan M, Ozcimen EE, Gullu H, Uckuyu A, Erdogan D, Zeyneloglu H \& Muderrisoglu H. Metformin therapy improves coronary microvascular function in patients with polycystic ovary syndrome and insulin resistance. Clinical Endocrinology $2006 \quad 65$ 75-80. (doi:10.1111/j.1365-2265. 2006.02551.x)

29 van der Meer RW, Rijzewijk LJ, de Jong HWAM, Lamb HJ, Lubberink M, Romijn JA, Bax JJ, de Roos A, Kamp O, Paulus WJ, Heine RJ, Lammertsma AA, Smit JWA \& Diamant M. Pioglitazone improves cardiac function and alters myocardial substrate metabolism without affecting cardiac triglyceride accumulation and high-energy phosphate metabolism in patients with wellcontrolled type 2 diabetes mellitus. Circulation 20091192069 2077. (doi:10.1161/CIRCULATIONAHA.108.803916)

30 Agarwal N, Rice SPL, Bolusani H, Luzio SD, Dunseath G, Ludgate M \& Rees DA. Metformin reduces arterial stiffness and improves endothelial function in young women with polycystic ovary syndrome: a randomized, placebo-controlled, crossover trial. Journal of Clinical Endocrinology and Metabolism 201095 722-730. (doi:10.1210/jc.2009-1985)

31 Jyothirmayi GN, Soni BJ, Masurekar M, Lyons M \& Regan TJ. Effects of metformin on collagen glycation and diastolic dysfunction in diabetic myocardium. Journal of Cardiovascular Pharmacology and Therapeutics 19983 319-326. (doi:10.1177/ 107424849800300407)

32 Xiao H, Ma X, Feng W, Fu Y, Lu Z, Xu M, Shen Q, Zhu Y \& Zhang Y. Metformin attenuates cardiac fibrosis by inhibiting the TGF $\beta 1$ Smad3 signaling pathway. Cardiovascular Research $2010 \mathbf{8 7}$ 504-513. (doi:10.1093/cvr/cvq066)

33 Khurana R \& Malik IS. Metformin: safety in cardiac patients. Heart 2010 96 99-102. (doi:10.1136/hrt.2009.173773)

34 Eurich DT, Majumdar SR, McAlister FA, Tsuyuki RT \& Johnson JA. Improved clinical outcomes associated with metformin in patients with diabetes and heart failure. Diabetes Care $2005 \mathbf{2 8}$ 2345-2351. (doi:10.2337/diacare.28.10.2345)

Received 27 July 2010

Accepted 2 August 2010 